\title{
Artigo Original \\ ENXERTO ÓSSEO AUTÓLOGO PARA DEFEITOS TIBIAIS NA ARTROPLASTIA TOTAL DE JOELHO
}

\author{
AUTOLOGOUS BONE GRAFT FOR TIBIAL DEFECTS ON KNEE TOTAL ARTHROPLASTY
}

\author{
Cezar Teruyuki KaWano', Nilson Roberto SeVerino²,
}

\begin{abstract}
RESUMO
Os joelhos osteoartrósicos acometidos por falhas ósseas importantes cursam com deformidade em varo ou valgo, causando limitação funcional das atividades diárias como dor, instabilidade e claudicação. Entre março de 1996 e janeiro de 2003 foram tratados 19 joelhos em 18 pacientes com artroplastia total primária de joelho, utilizando enxerto ósseo autólogo através da técnica modificada de Sculco para correção de grandes defeitos tibiais. Pela classificação utilizada em nosso serviço, 16 joelhos apresentaram lesão do tipo II e três, do tipo III. O tempo de seguimento pós-operatório variou de 8 a 82 meses, com média de 53,73 $\pm 23,43$ meses. Os resultados pós-operatórios foram semelhantes aos das artroplastias primárias e com incorporação inicial precoce do enxerto ósseo em média de $7,58 \pm 1,87$ meses. Houve colapso em um joelho na fase de remodelação óssea e não houve caso de infecção. O ângulo de flexão variou entre $90^{\circ}$ e $125^{\circ}$, com média de $105,27^{\circ} \pm 9,47^{\circ}$ e o ângulo femorotibial variou entre $170^{\circ}$ e $180^{\circ}$, com média de $175,33^{\circ} \pm 2,57^{\circ}$. Obtivemos valgo de $3^{\circ}$ a $8^{\circ}$ em $73 \%$ dos joelhos tratados. O objetivo deste estudo é analisar a eficácia da técnica modificada de Sculco para correção de grandes defeitos tibiais com enxerto ósseo autólogo, através da observação clínica e radiográfica.
\end{abstract}

Descritores: Joelho; Artroplastia do joelho; Enxerto ósseo autólogo.

\section{INTRODUÇÃO}

Os joelhos acometidos de falhas ósseas importantes cursam com deformidades angulares em varo ou valgo, causando durante as atividades diárias limitações funcionais como dor e claudicação, além de instabilidade.

Na osteoartrose avançada geralmente existe uma perda óssea no côndilo tibial e/ou côndilo femoral de diversas etiologias ${ }^{(1)}$, como artrose primária, seqüelas de fraturas, doenças erosivas, doenças reumáticas e condições avasculares.

Atualmente este tipo de deformidade com perda óssea está se tornando raro, pois as indicações de prótese são mais precoces não se esperando que o paciente adquira incapacidade estética e funcional, além de outros fatores como melhora dos desenhos dos componentes ${ }^{(2)}$, boa técnica de cimentação e instrumental preciso, o que aumenta a sobrevida das próteses ${ }^{(3)}$. No passado, como as artroplastias não apresentavam bons resultados $^{(1,4)}$, muitos joelhos com artrose resultavam em grandes perdas ósseas, com deformidade em varo ou valgo e instabilidade. Encontramos, na revisão da literatura, três fases da artroplastia do joelho: a primeira, relativa à técnica de interposição de materiais entre as linhas de osteotomia; a segunda, decorrente das falhas e problemas verificados, correspondendo às próteses em dobradiças e a terceira, na qual surgiram as próteses de substituição das superfícies articulares, atualmente utilizadas por nós.

\section{SUMMARY}

Osteoarthrosic knees with large bone defects usually develop as varus or valgus deformities, with daily functional disabilities such as pain, instability and limping. Between March 1996 and January 2003, 19 knees of 18 patients were treated through primary total knee arthroplasty using autologous bone graft using the Sculco modified technique to correct large tibial defects. Sixteen knees were assigned to group II and three to group III, according to the classification used in our medical service. Postoperative follow up period ranged from eight to 82 months, with an average of 53,73 $\pm 23,43$ months. Postoperative outcomes were similar to those of the primary arthroplasties, with early bone graft incorporation, within an average of $7,58 \pm 1,87$ months. Collapse was seen in one knee during bone remodeling stage, without infection. The range of motion was between $90^{\circ}$ and $125^{\circ}$, with an average of $105,27^{\circ} \pm 9,47^{\circ}$ and the femoral tibial angle was between $170^{\circ}$ and $180^{\circ}$, with an average of $175,33^{\circ} \pm 2,57^{\circ}$. Valgus angle ranging from $3^{\circ}$ to $8^{\circ}$ was obtained in $73 \%$ of the treated knees. The purpose of this study is to assess the effectiveness of the Sculco modified technique in correcting large tibial defects with autologous bone graft through clinical and radiographic observation.

Keywords: Knee; Arthroplasty; Replacement; autologous bone graft.

Técnicas cirúrgicas adequadas preconizam um bom alinhamento da angulação do joelho no plano frontal, próximo a um valgo de cinco a sete graus, equalização ligamentar, cortes precisos de acordo com os guias, bom apoio dos componentes para que não haja afundamentos, compensação dos defeitos ósseos por diversos materiais quando necessário e boa cimentação(18).

É unânime entre diversos autores ${ }^{(5-14)}$ a indicação de enxertos ósseos em grandes falhas, que chegam a ultrapassar $50 \%$ de um côndilo tibial e valores acima de cinco milímetros de profundidade.

Muitos dos joelhos com grandes defeitos tibiais requerem procedimentos tecnicamente difíceis e as chances de mau posicionamento são grandes, pois, além das perdas, em diversos casos estão associados a torções internas ou externas ao redor do eixo longo da tíbia.

O preenchimento da perda óssea poderá ser realizado por diferentes materiais, de acordo com a indicação e experiência do cirurgião. Além dos enxertos ósseos autólogos e homólogos, há o cimento de metilmetacrilato, utilizado com ou sem fixações com materiais de síntese, as cunhas de polimetilmetacrilato, as cunhas metálicas em próteses modulares e as próteses confeccionadas sob medida(15)

O objetivo deste estudo é avaliar a eficácia da técnica modificada de Sculco para correção dos defeitos tibiais com enxerto ósseo autólogo, através da observação clínica e radiográfica. 


\section{MATERIAL E MÉTODO}

\section{Material}

Em nossa série foram realizadas 19 correções de defeitos ósseos em prótese primária com enxerto ósseo autólogo em 18 pacientes, no período de março de 1996 a janeiro de 2003 (Tabela 1). Quanto ao sexo, 14 (78\%) eram mulheres e quatro (22\%), homens.

A idade variou entre 55 e 77 anos, com média de 66,10 \pm 6,78 anos.

Quanto ao joelho, 12 (63\%) eram direitos e sete (37\%), esquerdos.

Quanto aos côndilos tibiais, 16 (84\%) eram mediais e três (16\%), laterais.

Quanto à patologia, 17 (90\%) joelhos tinham osteoartrose primária e dois (10\%), artrite reumatóide.

Segundo a classificação de defeitos ósseos utilizada em nosso serviço ${ }^{(16)}, 16$ (84\%) pertenciam ao tipo II e três (16\%), ao tipo III (Tabela 2).

O tempo de seguimento pós-operatório variou de oito a 82 meses, com média de 53,73 $\pm 23,43$ meses.

\section{Método}

\section{Técnica cirúrgica}

Todos os pacientes foram submetidos à artroplastia primária total do joelho, com próteses cimentadas e cunhas de enxertos ósseos autólogos, através da técnica modificada de Sculco.

As osteotomias nas superfícies dos côndilos femorais e tibiais e da patela são realizadas de acordo com as orientações determinadas pelos guias do instrumental. As equalizações ligamentares e liberações das partes moles são procedidas quando necessárias.

\section{Técnica modificada de Sculco}

Nesta variante técnica, é feita a regularização das extremidades do defeito ósseo, ressecando mínima quantidade possível de osso. O osso subcondral, esclerótico e avascular, é cruentizado com formão laminado ou serra pneumática e perfurações com broca de um quarto de polegada. Com a finalidade de criar uma superfície ideal para prótese, a falha óssea é preenchida pelo enxerto autólogo, obtido dos cortes ósseos dos côndilos femorais e locado na área receptora, sem fixação com fios ou parafusos. A prótese é cimentada sobre os côndilos tibiais, dando contenção ao enxerto (Figuras 1 e 2). Em dois casos onde havia defeito ósseo maior que meio côndilo tibial, foi associada haste de extensão intramedular de cerca de $70 \mathrm{~mm}$ de comprimento, com a finalidade de dissipar em 30\% a carga vertical aplicada sobre a prótese e de melhorar a fixação e estabilização do componente tibial (Figura 3).

\section{Pós-operatório}

Os pacientes foram avaliados no pós-operatório quanto à amplitude de flexão, ângulo femorotibial, incorporação inicial do enxerto através das observações radiográficas e possíveis complicações clínicas (Tabela 3).

\section{Avaliação Radiográfica}

São avaliadas as radiografias de joelho no pós-operatório imediato com o objetivo de observar o posicionamento do enxerto na falha óssea tibial.

As avaliações posteriores são realizadas a cada dois meses e, quando necessárias, mensalmente, com o intuito de observar o início da incorporação óssea através da transposição do trabeculado ósseo do leito hospedeiro para o enxerto ósseo.

\section{RESULTADOS}

Obtivemos a consolidação e incorporação inicial dos enxertos ósseos nos 19 joelhos, que ocorreram num período de quatro a 12 meses, com média de 7,58 1,87 meses. O enxerto 19 (5\%) incorporou em quatro meses e os enxertos 1, 14, 16, 17 e 18 (26\%) incorporaram no período de seis meses; os enxertos 3, 4, 6 e 13 (21\%) em sete meses; os enxertos 2, 5, 8 e 15 (21\%) em oito meses; os enxertos 9 e 10 (10\%) em nove meses; os enxertos 7 e 11 (10\%) em dez meses e o enxerto 12 (5\%) em 12 meses (Tabela 4).

A amplitude de flexão variou de $90^{\circ}$ a $125^{\circ}$, com média de $105,27^{\circ} \pm 9,47^{\circ}$ e a angulação femorotibial variou de $170^{\circ}$ a $180^{\circ}$, com média de $175,33^{\circ} \pm 2,57^{\circ}$. Obtivemos a angulação de três a oito graus de valgo em $73 \%$ dos joelhos operados.

Como complicação, houve um (5\%) caso de fragmentação com absorção, que ocorreu no $18^{\circ}$ mês de pós-operatório na fase de remodelação óssea. Não houve caso de infecção.

\section{DISCUSSÃO}

Materiais diversos com técnicas variadas foram descri$\operatorname{tas}^{(1,7,9,11,12,14,15,17)}$, com objetivo de compensar o defeito ósseo primário ou secundário. McKeever ${ }^{(18)}$, fez um dos primeiros relatos da utilização do enxerto ósseo autólogo obtido da crista do ilíaco para a reparo do defeito ósseo na superfície do côndilo tibial.

\begin{tabular}{|c|c|c|c|c|c|c|c|}
\hline Joelho & Idade & Sexo & Lado & Planalto & Doença & Classif. & Pós-op. \\
\hline 1 & 55 & $\mathrm{~F}$ & $\mathrm{D}$ & $\mathrm{med} /$.lat. & AR & IIII & 82 meses \\
\hline 2 & 55 & $\mathrm{~F}$ & $E$ & med./lat. & $A R$ & III & 80 meses \\
\hline 3 & 65 & $\mathrm{~F}$ & D & med. & $O A$ & 11 & 75 meses \\
\hline 4 & 68 & M & D & med. & $O A$ & ॥ & 74 meses \\
\hline 5 & 63 & $\mathrm{~F}$ & E & med. & $O A$ & II & 71 meses \\
\hline 6 & 63 & $\mathrm{~F}$ & D & med. & $O A$ & II & 71 meses \\
\hline 7 & 72 & $\mathrm{~F}$ & D & med. & $O A$ & II & 66 meses \\
\hline 8 & 68 & $\mathrm{~F}$ & D & med. & $O A$ & II & 64 meses \\
\hline 9 & 67 & M & D & med. & $O A$ & II & 62 meses \\
\hline 10 & 64 & $\mathrm{~F}$ & $E$ & lat. & $\mathrm{OA}$ & II & 57 meses \\
\hline 11 & 73 & $\mathrm{~F}$ & $E$ & med. & $O A$ & II & 55 meses \\
\hline 12 & 77 & $\mathrm{~F}$ & D & lat. & $O A$ & II & 53 meses \\
\hline 13 & 58 & $M$ & $\mathrm{E}$ & med. & $O A$ & II & 52 meses \\
\hline 14 & 61 & $\mathrm{~F}$ & $E$ & med. & $\mathrm{OA}$ & II & 52 meses \\
\hline 15 & 67 & $\mathrm{~F}$ & D & med. & $O A$ & II & 51 meses \\
\hline 16 & 58 & $M$ & D & méd. & $O A$ & II & 28 meses \\
\hline 17 & 74 & $\mathrm{~F}$ & $E$ & lat. & $O A$ & II & 11 meses \\
\hline 18 & 73 & $\mathrm{~F}$ & D & med./lat. & $\mathrm{OA}$ & III & 09 meses \\
\hline 19 & 75 & $\mathrm{~F}$ & D & med. & $O A$ & II & 08 meses \\
\hline Média & \multicolumn{2}{|c|}{$66,10 \pm 6.78$ anos } & & & & \multicolumn{2}{|c|}{$53,7 \pm 23,43$ meses } \\
\hline
\end{tabular}

Fonte: $\mathrm{HMCC}$

Legenda: $F=$ feminino; $M=$ masculino; $D=$ direito, $E=$ esquerdo; med.=medial; lat. = lateral; $A R=$ artrite reumatóide; $A O=$ osteoartrose; Classif. = classificação; Pós$o p .=$ pós-operatório

Tabela 1 - Perfil dos pacientes estudados.

\begin{tabular}{ccc}
\hline Tipo & № compartimentos & Profundidade \\
\hline I & 1 ou 2 & Superficial \\
II & 1 & Profundo \\
III & 2 & No minimo 1 profundo (1 ou 2) \\
\hline
\end{tabular}

Fonte: HMCC

Adaptado de Kawano et al11

Tabela 2 - Classificação dos defeitos ósseos.

\section{Técnicas cirúrgicas}

Existem várias técnicas utilizadas para implantes de enxertos ósseos autólogos ou homólogos. Os ossos homólogos provêm de bancos de ossos devidamente testados e preparados e os autólogos são retirados dos cortes realizados nos côndilos femorais e tibiais nas próteses primárias e, como alternativa, podem ser retirados da crista do ilíaco em bloco, tanto para lesões primárias como para revisões.

Windsor et al. ${ }^{(14)}$, descreveram a técnica preconizada por Insall e a de Sculco. Na técnica de Insall, é retirado um fragmento de forma trapezoidal no local do defeito ósseo, implantando-se no espaço criado um enxerto autólogo ou homólogo de mesmo formato, fixando-o com fios inoxidáveis, resultando em uma superfície plana no côndilo tibial ideal para cimentação do componente protético. Na de Scul$\mathrm{co}$, que é uma das mais utilizadas atualmente, cria-se uma superfície lisa, através de um corte oblíquo no local da perda óssea com serra pneumática, colocando o enxerto no local e fixandoo com fios inoxidáveis ou parafusos. Em nossa série foi utiliza- 


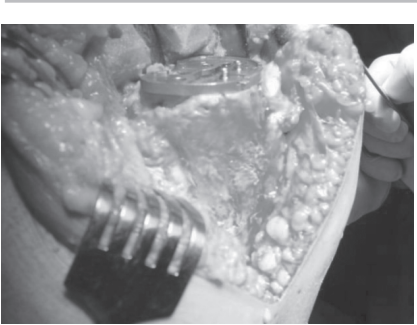

Figura 1 - Área do defeito do hemicôndilo tibial a ser preenchida com enxerto ósseo - imagem intra-operatória

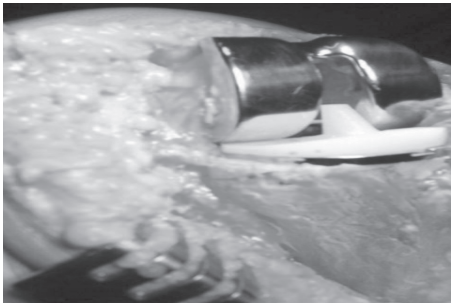

Figura 2 - Prótese totalcomponente tibial, cimentado sobre o côndilo tibial e o enxerto ósseo - imagem intra-operatória

da uma variante da técnica de Sculco.

A utilização da técnica modificada de Sculco em nosso trabalho foi devida ao fato de que essa técnica resseca menos osso sadio que a técnica original; toda vez que a osteotomia é realizada com a serra pneumática no local da falha óssea, uma pequena parte anterior e posterior do defeito é retirada junto com o osso esclerótico, pois os defeitos não apresentam uma superfície regular oblíqua e na técnica original tem-se que realizar essa regularização.

\section{Outros materiais}

Vários materiais são utilizados para compensação dos defeitos, tais como: cimento de metilmetacrilato, com ou sem fixação com parafuso; cunhas metálicas modulares ou confeccionadas sob medida junto com a prótese; cunhas de polimetilmetacrilato e os enxertos ósseos autólogos e homólogos.

A escolha do material depende da experiência de cada cirurgião e sua preferência e, muitas vezes, a indicação estará de acordo com a forma, o tamanho e a profundidade do defeito ósseo.

Brooks et al. ${ }^{(15)}$, estudaram o percentual de deflexão que cada material intercalado no defeito poderia causar quando se aplica uma força vertical sobre o conjunto e constataram que os piores resultados, com alto índice de deflexão, se deram quando o cimento de metilmetacrilato, com ou sem fixação com parafuso, foi utilizado. As cunhas de polimetilmetacrilato e as metálicas resultaram em bons índices e os meIhores, quando as próteses confeccionadas sob medida foram usadas. A interpretação dos resultados depende da deflexão que produz o material intercalado (quanto menor o índice, maior será a rigidez de fixação).

É de grande importância o uso

\begin{tabular}{cccc}
\hline Joelho & Inc. Enx. & Áng. Flexão & Âng. F. T. \\
\hline 1 & 06 meses & $100^{\circ}$ & $176^{\circ}$ \\
2 & 08 meses & $*$ & $*$ \\
3 & 07 meses & $105^{\circ}$ & $175^{\circ}$ \\
4 & 07 meses & $110^{\circ}$ & $178^{\circ}$ \\
5 & 08 meses & $105^{\circ}$ & $174^{\circ}$ \\
6 & 07 meses & $115^{\circ}$ & $177^{\circ}$ \\
7 & 10 meses & $95^{\circ}$ & $173^{\circ}$ \\
8 & 08 meses & $90^{\circ}$ & $175^{\circ}$ \\
9 & 09 meses & $105^{\circ}$ & $178^{\circ}$ \\
10 & 09 meses & $105^{\circ}$ & $178^{\circ}$ \\
11 & 10 meses & $100^{\circ}$ & $177^{\circ}$ \\
12 & 12 meses & $95^{\circ}$ & $180^{\circ}$ \\
13 & 07 meses & $120^{\circ}$ & $174^{\circ}$ \\
14 & 06 meses & $105^{\circ}$ & $177^{\circ}$ \\
15 & 08 meses & $110^{\circ}$ & $175^{\circ}$ \\
16 & 06 meses & $110^{\circ}$ & $175^{\circ}$ \\
17 & 06 meses & $125^{\circ}$ & $172^{\circ}$ \\
18 & 06 meses & $90^{\circ}$ & $170^{\circ}$ \\
19 & 04 meses & $110^{\circ}$ & $172^{\circ}$ \\
\hline Média & $7,58 \pm 1.87$ meses & $105,27^{\circ} \pm 9,47^{\circ}$ & $175,33^{\circ} \pm 2,57^{\circ}$ \\
\hline
\end{tabular}

Inc.Enx. = incorporação do enxerto - Âng. Flexão = ângulo de flexão Âng. F.T. $=$ ângulo femorotibial - * fragmentou

Tabela 3 - Resultados pós-operatórios.

\begin{tabular}{clc}
\hline Meses & Pacientes & Percentual \\
\hline 04 & 19 & $5 \%$ \\
06 & $01,14,16,17,18$ & $26 \%$ \\
07 & $03,04,06,13$ & $21 \%$ \\
08 & $02,05,08,15$ & $21 \%$ \\
09 & 09,10 & $10 \%$ \\
10 & 07,11 & $10 \%$ \\
12 & 12 & $5 \%$ \\
\hline
\end{tabular}

Tabela 4 - Tempo de consolidação e incorporação inicial dos enxertos.
Figura 3 - Prótese total com haste de extensão tibial intramedular de 70 milímetros radiografia em posição anteroposterior

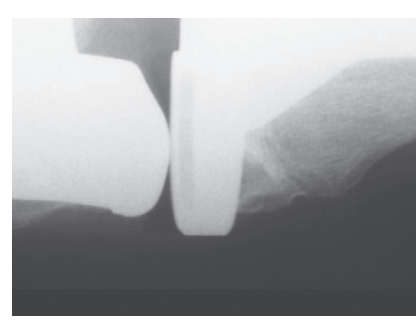

Figura 4 - Incorporação do enxerto ósseo autólogo ao defeito tibial - imagem radiográfica evidenciando a transposição do trabeculado ósseo.

\section{Enxerto ósseo}

\section{Enxertos homólogos}

enxertos homólogos apresentam um fator de relevância a hospedeiros, levando a uma incorporação mais lenta ou parcial, com maior incidência de falha em relação aos autológos ${ }^{(5,17)}$ A indicação do enxerto autólogo ou homólogo depende das condições técnicas do cirurgião, da existência do banco de osso e da quantidade de enxerto a ser utilizado. É preciso, porém, estar atento ao uso dos homólogos por causa do maior índice de infecção e transmissão de doenças como HIV, hepatite B e C, sífilis, bactérias aeróbicas e anaeróbicas e vírus linfocitários.

\section{Enxertos autólogos}

Os enxertos autólogos têm sido uma boa opção no reparo dos defeitos ósseos, pois é seguro quanto à transmissão de doenças, tem baixo índice de infecção e fragmentação, com incorporação do enxerto em curto prazo por ser bom osteoindutor e osteocondutor - sem o custo adicional das próteses confeccionadas sob medida e não produz reação imunológica como os homólogos.

\section{Incorporação óssea}

Consolidação e incorporação Existe um consenso entre os autores revisados quanto à indicação do reparo das perdas ósseas primárias ou secundárias com enxerto autólogo ${ }^{(7,9,14,15)}$, que apresenta consolidação e incorporação óssea em curto prazo e bons resultados.

Quando é utilizado o enxerto ósseo autólogo ou homólogo, é esperada a consolidação e incorporação do mesmo, porém os significados biológicos dessas terminologias são diferentes; a primeira é apenas a fusão óssea da haste de extensão intramedular de $70 \mathrm{~mm}$ nos casos de grandes defeitos ósseos, pois ela absorve junto com envoltório cortical a força de compressão vertical em mais de 30\%, evitando a fragmentação do enxerto e o colapso do osso metafisário(15), além de propiciar melhor estabilização e fixação do componente protético.

entre o enxerto e o osso hospedeiro e a segunda, a remodelação do enxerto, que passa por diversas etapas de modificações biológicas progressivas até a substituição total do enxerto pelo osso hospedeiro ${ }^{(5,17)}$.

Destacamos, entre as várias funções do enxerto ósseo, a osteogênese e o suporte mecânico e, de acordo com a finalidade a 
que se destina, uma função pode ser mais valiosa que a outra Em nosso trabalho, as duas foram de grande valia, pois, até a incorporação, o apoio da prótese foi realizado.

A osteogênese é a ossificação verificada através da substituição do enxerto, realizada em sua maior parte pelas células provenientes do osso hospedeiro, com a participação das células do enxerto ósseo na interface com o leito receptor, que sobrevivem por difusão. A grande participação dos enxertos dá-se em relação ao processo de osteoindução e osteocondução(17)

\section{Tempo de incorporação}

A maior expectativa pós-operatória é quanto à incorporação do enxerto ósseo autólogo no defeito tibial, representada na radiografia pela transposição do trabeculado ósseo ao implante ${ }^{(7,12,13)}$, que em nossa série, iniciou-se em média com 7,58 $\pm 1,87$ meses (Figura 4). Dorr et al. ${ }^{(7)}$, obtiveram incorporação inicial em seis meses, porém não determinaram o tempo para completa remodelação; Windsor et al. ${ }^{(14)}$, referiram o início da remodelação entre quatro e oito meses e Wilde et al. ${ }^{(13)}$, com enxertos homólogos, afirmaram que o tempo de incorporação inicial é variável, sendo o caso mais precoce iniciado aos três meses.

\section{Fases da incorporação}

Segundo Goldberg e Stevenson ${ }^{(17)}$, as fases que se observam até a remodelação ou incorporação total são a inflamação, revascularização, indução osteogênica, condução osteogênica e remodelação.

Bauer e Muschler ${ }^{(5)}$, relataram que até a incorporação total se observou a organização do hematoma, inflamação, invasão por vasos sangüíneos, reabsorção focal pelos osteoclastos e finalmente formação óssea.

\section{Fragmentação e absorção}

As complicações mais temidas são a fragmentação do enxerto com absorção e a infecção. Quanto à fragmentação, não união e absorção do enxerto, vários autores ${ }^{(5,7,17)}$ atribuíram esses problemas à falha no alinhamento, não equalização de partes moles, cargas excessivas e preparo inadequado do leito receptor, com deficiência na cruentização do osso ebúrneo, através de perfurações ou simples ressecção, de acordo com as técnicas descritas, como as principais causas.

Dorr et al. ${ }^{(7)}$, em 24 joelhos tratados com enxertos autólogos obtiveram dois casos de não união e um colapso; Laskin et al. ${ }^{(9)}$, reportaram em sua série de 26 joelhos tratados com enxertos autólogos, quatro fragmentações com absorção no primeiro ano de acompanhamento, atribuindo o mau resultado ao tamanho das perdas ósseas e á má técnica utilizada em relação ao alinhamento necessário; Mnaymneh et al. ${ }^{(10)}$, em 14 joelhos tratados com enxertos homólogos, apresentaram dois casos de não união e fratura; Stockley et al.(11), também utilizando enxertos homólogos, obtiveram dois enxertos fraturados em 20 joelhos; Ghazavi et al. ${ }^{\left({ }^{8}\right)}$ observaram uma fratura e uma não união com o uso dos homólogos em 30 joelhos submetidos a revisão; Clatworthy et al. ${ }^{(6)}$, em 50 joelhos tratados com enxertos homólogos, obtiveram cinco casos de reabsorção e dois de não união. Obtivemos um caso nessas condições entre os 19 enxertos autólogos de nossa série.

\section{MÉTODOS DE AVALIAÇÃO}

As falhas na remodelação dos enxertos ósseos são determinadas basicamente pelo acompanhamento clínico, controles radiográficos periódicos, tomografia, cintilografia e biópsia(5,7)

\section{RESULTADOS CLÍNICOS}

\section{Alinhamento no plano frontal}

O alinhamento do joelho no plano frontal é de crucial importância para a sobrevida da prótese ${ }^{(19)}$ e para o sucesso da consolidação e incorporação do enxerto. Dorr et al. ${ }^{(7)}$, consideram o mau alinhamento como uma das causas principais dessas fragmentações, sugerindo como ideal cinco a oito graus de valgo; Windsor et al. ${ }^{(14)}$, recomendaram entre sete a nove graus de valgo; Wilde et al. ${ }^{(13)}$ e Tsahakis et al. ${ }^{(12)}$, apresentaram em suas séries resultado médio de quatro graus de valgo. Em nossa série as angulações variaram de zero a dez graus de valgo, com média de $4.7^{\circ} 2,57^{\circ}$. Obtivemos o valgo entre três e oito graus em $73 \%$ dos joelhos

\section{Índice de flexão}

Quanto à flexão, Wilde et al. ${ }^{(13)}$, obtiveram uma média de $105^{\circ}$. Mnaymneh et al..$^{(10)}$, média de $92^{\circ}$ variando de $60^{\circ}$ a $105^{\circ}$; Harris et al. ${ }^{(20)}$, apresentaram média de $104^{\circ}$, com variação de $60^{\circ}$ a $125^{\circ}$. Em nossa série, tivemos índice de $90^{\circ}$ a $125^{\circ}$, com média de $105,27^{\circ} \pm 9,47^{\circ}$

\section{Complicações}

Como complicação houve fragmentação do enxerto, cuja razão não foi determinada. A paciente é portadora de artrite reumatóide, faz uso de medicamentos imunossupressores e em sua cirurgia foi utilizado um grande enxerto ósseo, pois sua lesão era maior que meio côndilo tibial medial. Esses fatores talvez tenham contribuído para a causa dessa fragmentação e absorção.

\section{CONCLUSÃO}

O utilização do enxerto autólogo através da técnica modificada de Sculco constitui bom método de reparo biológico de defeitos ósseos dos côndilos tibiais, com consolidação e incorporação inicial em curto prazo, mínima incidência de fragmentação e absorção, permitindo bons índices de alinhamento no plano frontal e de flexão dos joelhos.

\section{REFERÊNCIAS BIBLIOGRÁFICAS}

1- Lotke PA, Wong RY, Ecker ML. The use of methylmethacrylate in primary total knee replacements with large tibial defects. Clin Orthop 1991; 270:288-94.

2- Insall JN, Ranawat CS, Scott WN, Walker P. Total condylar knee replacement. preliminary report. Clin Orthop 1976; 120:149-54.

3- Font-Rodriguez DE, Scuderi GR, Insall JN. Survivorship of cemented total knee arthroplasty. Clin Orthop 1997; 345:79-86.

4- Insall JN, Ranawat CS, Aglietti P, Shine J. A comparison of four models of total knee-replacement prostheses, J Bone Joint Surg Am 1976; 58:754-65.

5- Bauer TW, Muschler GF. Bone graft materials. An overview of the basic science. Clin Orthop 2000; 371:10-27.

6- Clatworthy MG, Ballance J, Brick GW, Chandler HP, Gross AE. The use of structural allograft for uncontained defects in revision total knee arthroplasty. A minimum five-year review. J Bone Joint Surg Am 2001; 83:404-11.

7- Dorr LD, Ranawat CS, Sculco TA, McKaskill B, Orisek BS. Bone graft for tibial defects in total knee arthroplasty. Clin Orthop 1986; 205:153-65.

8- Ghazavi MT, Stockley I, Yee G, Davis A, Gross AE. Reconstruction of massive bone defects with allograft in revision total knee arthroplasty. J Bone Join Surg Am 1997: 79:17-25

9- Laskin RS. Total knee arthroplasty in the presence of larg bony defects of the tibia and marked knee instability. Clin Orthop 1989; 248:66-70.

10- Mnaymneh W, Emerson RH, Borja F, Head WC, Malinin TI. Massive allografts in salvage revisions of failed total knee arthroplasties. Clin Orthop 1990; 260:144-53.
11- Stockley I, McAuley JP. Gross AE. Allograft reconstruction in total knee arthroplasty. J Bone Joint Surg Br 1992; 74:393-7

12- Tsahakis PJ, Beaver WB, Brick GW. Technique and results of allograft reconstruction in revision total knee arthroplasty. Clin Orthop 1994: 303:86-94.

13- Wilde AH, Schickendantz MS, Stulberg BN, Go RT. The incorporation of tibial allografts in total knee arthroplasty. J Bone Joint Surg Am 1990; 72:815-24.

14- Windsor RE, Insall JN, Sculco TP. Bone grafting of tibial defects in primary and revision total knee arthroplasty. Clin Orthop 1986; 205:132-7.

15- Brooks PJ, Walker PS, Scott RD. Tibial component fixation in deficient tibial bone stock. Clin Orthop 1984; 184:302-8.

16- Kawano CT, Romano NO, Monteiro AC. Classificação dos defeitos ósseos e métodos de correção nas artroplastias primárias de joelhos. Rev Bras Ortop 1998; 33:287-90

17- Goldberg VM, Stevenson S. Natural history of autografts and allografts. Clin Orthop 1987: 225:7-16.

18- McKeever DC. Tibial plateau prothesis. Clin Orthop 1960; 18:86-95.

19- Ritter MA, Faris PM, Keating EM, Meding JB. Postoperative alignment of total knee replacement. Its effect on survival. Clin Orthop 1994: 299:153-6.

20- Harris Al, Poddar S, Gitelis S, Sheinkop MB, Rosenberg AG. Arthroplasty with a composite of an allograft and a prosthesis for knees with severe deficiency of bone. J Bone Joint Surg Am 1995; 77:373-86. 